\title{
As RELAÇÕES ENTRE CIÊNCIA E POESIA NA OBRA DO POETA ROMENO ION BARBU. MATEMÁTICA COMO JOGO
}

\author{
LINKS BETWEEN SCIENCE AND POETRY IN THE WORKS OF THE \\ Romanian poet lon Barbu. Mathematics as a game
}

Virginia Popović

Universidade de Novi Sad

Novi Sad, Sérvia

\section{Resumo}

Este artigo analisa as influências do jogo e dos símbolos matemáticos na obra do poeta moderno Ion Barbu, as relaçôes entre ciência e arte em sua poesia, além de propor uma leitura da teoria dos jogos como arte poética. A obra de Barbu é imbuída de símbolos matemáticos, razão pela qual foi vista pela crítica como original, uma novidade na literatura romena. $\mathrm{O}$ poeta e matemático Ion Barbu (Dan Barbilian) é um dos mais conhecidos poetas do país, e seu trabalho não só passou por diversas fases representativas como também sofreu diversas mudanças no plano da linguagem. Assim, o tema do jogo varia de acordo com a fase poética que analisamos. A crítica do jogo como ars poetica, no trabalho de investigadores romenos quanto no de estrangeiros, é o ponto de partida deste artigo, que, por sua vez, tem por objetivo demonstrar que o jogo é, além de um tropo cultural e literário, um modo de vida. A própria literatura é um jogo de espaço e de tempo que atravessa diferentes épocas e estilos. A poesia é um jogo de palavras, criadora de um espaço imaginário complexo e fascinante. A vida se desdobra no espaço de um jogo intelectual, em um mundo criado pela mente, no qual tudo é diferente da vida real e interconectado por laços que não seguem uma lógica cotidiana. $\mathrm{O}$ jogo, portanto, é um elemento tipicamente poético, e toda forma poética parece estar intimamente ligada à estrutura do jogo.

\section{Abstract}

The paper explores and analyzes the influences of game and mathematical symbols on the poetry of the Romanian modern poet Ion Barbu. The paper presents the analysis of the theories of game as a poetic art as well as the analysis of the links between science and poetry in the

\section{Rezumat}

Lucrarea de faţă cercetează influenţa jocului și a simbolurilor matematice asupra poetului român modern, Ion Barbu. Lucrarea reprezintă teoriile cercetătorilor cu privire la jocul ca artă poetică, la fel legătura dintre știinţă şi poezie în opera lui Ion Barbu, ajungându-se la concluzia
Palavras-chave: Jogo; matemática; poesia; Ion Barbu; símbolos; modernismo.

Keywords: Game; mathematics; poetry; Ion Barbu; symbols; modernism.

Cuvinte cheie: Joc; matematică; poezie; Ion Barbu; simbol; modernism. 
works of Ion Barbu - links which led to the conclusion that his poetry is imbued with mathematical symbols. This was the reason why literary critics reviewed his work as original and a novelty in Romanian literature. Poet and mathematician Ion Barbu (Dan Barbilian) became known as one of the most significant modern poets of Romania, Barbus' lyric went not only through different phases distinct by various specific representations, but it also went through language modifications. Thus the motive of the game which we encounter in Barbu's poetry changes according to the literary phase through which the poet goes. The analysis of game as ars poetica by critics and other foreign and Romanian researchers represents the point of departure of this paper while the goal of this research is to identify those components which demonstrate that game is not only a cultural and literary topic but also a way of life. Literature itself is a game of time and space, a game of different eras and fashions. Poetry is a game of words and a creator of a fascinating imaginary and complex space. Life unfolds within the space of an intellectual game, in a world created by the mind where things are different from those in real life and linked with links other than the logical ones. Game is thus an element that belongs within the field of poetry and every poetic form seems closely tied to the structure of the game. că poezia lui se întrepătrunde cu simbolurile matematice. Din acest punct de vedere, poezia lui Ion Barbu este caracterizată de criticii literari ca originală și inedită în literatura română. Poetul și matematicianul Ion Barbu/ Dan Barbilian este prezentat ca unul dintre cei mai de seamă poeţi moderni români, asociiându-l cu cele mai mari nume ale poeziei românești. Ion Barbu urmărește trei faze în exprimarea operei lui Barbu: etapa parnasiană, etapa, etapa baladesc-orientală și etapa ermetică. Având ca punct de pornire analizele deja efectuate ale jocului ca artă poetică făcute de anumiţi cercetători români și străini, unul dintre principalele obiective este expunerea componentelor ce conturează ideea că jocul nu este doar o temă culturală și literară, ci şi un mod de existenţă. Literatura însăși este un joc al timpului și al spaţiului, al mișcării epice semnificative, al epocilor și al modelor. Poezia e un joc de cuvinte care creează un spaţiu imaginar, de o complexiatate fascinantă. Viaţa se desfăşoară într-un spaţiu de joc al minţii, într-o lume proprie pe care și-o creează mintea, o lume în care lucrurile au alt chip decât în viaţa obişnuită și sunt conectate între ele prin alte legături decât prin cele logice. Jocul este un element atât de inerent naturii poeziei, iar fiecare formă a poeticului pare strâns legată de structura jocului.

Ion Barbu é um poeta do entreguerras, representativo de um estilo literário original, o hermetismo - tal qual Blaga é o representante maior do expressionismo, V. Voilescu, do mítico, e Bacovia, do simbolismo. Barbu compreendeu a fundo as reformas de Poe e Rimbaud, suas tentativas de "purificar" a alma romântica da poe- 
sia, e as levou adiante: buscou a superação do estágio descritivo do fazer poético por meio de uma generalidade que lhe abrisse múltiplos caminhos e possibilidades de expressáo. Sua fortuna crítica é vasta e contraditória, dada a complexidade hermenêutica da obra, que figura entre as mais enigmáticas da literatura romena - e da literatura da Europa como um todo. No que diz respeito à contribuição romena para a arte europeia, a ressonância da obra de Barbu só é comparável à da poética expressionista de Lucian Blaga, sua poesia e seus textos teóricos.

Blaga definiu a criação expressionista como uma incorporação de determinados valores, dentre os quais o mais elevado seria o absoluto. Barbu não diz outra coisa quando fala de "condição geométrica, e, para além dela, o êxtase". Não nega a capacidade da poesia de elevar-se ao absoluto, "em direçáo ao conhecimento que cura, mas [admite] sim, e somente, a impossibilidade de atingir o estado de graça que possibilita a criação desse tipo de poesia. [...] $\mathrm{O}$ silêncio, o drama do dizer, o trágico que se exprime pela expressão, tudo isso pode ser encontrado em grande parte da poesia romena".*

A publicação da coleção Mirrored Play [Jogo espelhado] foi fruto de uma aposta com Tudor Vianu, que duvidou que Barbu pudesse escrever poesia (outras fontes nos contam uma versão diferente, um ajuste: se Barbu provasse ser capaz de publicar poesia, Vianu analisaria criticamente o trabalho). Os poemas são de difícil compreensão. Ao passo que alguns críticos consideram Barbu um poeta hermético que escreve em linguagem abstrata, comentadores mais recentes "ressaltam seus esforços no sentido de, segundo o próprio autor, abster-se da ,competição entre formas individuais', isto é, despersonalizar a expressão". * O ciclo Mirrored Play foi traduzido para diversos idiomas, inclusive para o sérvio, de modo que sua circulação é global. Barbu se utiliza de conceitos matemáticos, sendo o mais frequente deles a noção de grupo (uma massa matematicamente estruturada cujos elementos podem se reunir segundo determinada lei): "Out of a clock, inferred, the depth of this peaceful peak, / Come through the mirror into the healing azure, Cutting through the drowned rough herds, I In ponds of water, an ever purer mirrored play." A compreensão da obra barbiliana pressupóe a aná-

\footnotetext{
1 "De um relógio, inferido, a profundidade deste pico pacífico,/ Através do espelho vem a este cerúleo curativo,/ Rasgando a afogada massa áspera,/ Em lagos d'água, um mais e mais puro jogo espelhado." (N. do T.)
}

* (RUJA, Alexandru. Hermeneut în luma clasicilor. In: Orizon, n.5, v. 20, 30 mai. 2008: 11.)

* (POP, lon. Jocul poeziei. Bucureşti: Editura Carta Românească, 1985: 148.) 
lise por gradação. O matemático Alexandru Pantazi, em seu livro Unpublished Pages - Dan Barbilian, afirmou, sobre Ion Barbu:

Aqueles matemáticos romenos que criaram algo no campo científico sem dúvida tinham talento. Barbilian tem também o gênio. Barbilian era um pensador extremamente original e profundo. A matemática provavelmente lhe deu um espaço mais vasto do que a poesia para pôr esse pensamento em prática. Felizmente para sua obra, mas náo necessariamente para sua vida pessoal, Barbilian conseguiu eliminar de sua vida tudo aquilo que não contribuía para suas empreitadas intelectuais.

Ion Barbu foi professor universitário até o fim da vida. Já nos últimos anos de sua carreira, ministrava cursos especiais frequentados por um reduzido número de bons alunos. Após sua morte, grande parte de seus escritos didáticos e teóricos no campo da matemática foi publicada. Esses manuscritos estavam espalhados por diversos cadernos e folhas avulsas. Anotaçóes foram encontradas nas margens dos muitos números da Gazeta Matematică que Barbu possuía, publicados antes da I Guerra Mundial. Depois desse período, ele abandonou o espaço literário e passou a se dedicar completamente à matemática, voltando à escrita artística somente em raras ocasióes. Seu trabalho científico era reconhecido em toda a Europa, sobretudo por sua conceituação dos "espaços barbilianos" na geometria. Wladimir Boskoff e Bogdan Suceavǎ publicaram um interessante artigo sobre esses "espaços" na revista Observator Cultural (n. 286, de setembro de 2005) intitulado "The Story of 'Barbilian spaces', Or What Else Happened after Mirrored Play" [A história dos "espaços barbilianos", ou O que mais aconteceu após Mirrored Play]. Atualmente, Barbu é reconhecido por seu real valor, tanto como matemático quanto como poeta.

Conhecer a obra de Barbu, perceber seu vasto universo de signifcação, expresso em linguagem lacônica e dentro de um rigoroso e elaborado sistema de signos, apresenta dificuldades para o leitor moderno:

A geometrização do espaço poético, a espiritualização do espaço matemático; a essencialização da percepção lírica, a individualização do discurso algébrico - essas são as coordenadas que, na obra de Barbu, fixam axiomaticamente a passagem do real para o espaço do puro Conhecimento. O discurso matemático, assim como o poético, bebem na fonte única e bela do Conhecimento Superior. A estilização da imagem poética, tal qual a estilização de uma demonstração matemática, ao ponto no qual passam a expressar uma 
Ideia em sua forma mais pura e abstrata, na forma mais próxima à essência mesma do conhecimento, é o "signo" ["sign”] a que aspira a criação barbi(li)ana. A aspiração gnóstica, portanto, o coloca ao lado dos grande pensadores do século XIX.*

Como poeta, "o lugar de Ion Barbu na literatura romena (e na europeia) parece ser singular. [...] A experiência poética por meio da construção deliberada, imposta pelo próprio autor, de fato é única. Não conhecemos outro poeta que tenha combinado, com tanta síntese lirica e condensação, os mais abstratos conceitos e as mais espontâneas inspiraçóes".* Como matemático, Dan Barbilian inventou os espaços que hoje levam seu nome, pensando em "outros modos" de existência matemática:

A crise científica da civilização grega foi a impossibilidade de conceber os números irracionais. Não a conquista romana, mas sim a incapacidade de superar certos preconceitos concernentes ao rigor matemático, de aceitar outros modos de existência matemática, foi o que ofuscou e enfraqueceu o gênio grego.*

A "relativização" do discurso matemático e a abertura para novas perspectivas e abordagens são os indícios de uma mente matemática extraordinária.

A obra, seja a poética, seja a matemática, evidencia os sinais de um destino único, não somente no espaço cultural romeno, mas também no da cultura universal. Ion Barbu "é o poeta mais difícil, não só da literatura romena”, ${ }^{*}$ esta dificuldade advém da "existência de um objeto unívoco e imaginário, não dito, circunscrito somente pela metodologia peculiar do matemático".* Eis o que diz Lovinescu sobre a poesia de Barbu:

Desde os primeiros versos, percebi um notável talento poético. Sburătorul tem a honra de franquear suas páginas a esse poeta chamado Ion Barbu. Ninguém poderá ignorar a visão genética, a intricada expressividade, a relativa sobriedade desse jovem que evoca, em versos gélidos e belos, a poesia dos poderes da natureza, da matéria inerte, da pretensão universal e dos mistérios da germinação. $\mathrm{O}$ vigor geométrico e a novidade conceitual, bem como a maestria formal, nos asseguram que a literatura romena foi enriquecida por um novo talento.

Ion Barbu escolheu escrever "uma poesia críptica, essencializada, imbuída de enigmas; poesia de iniciação”.*

Quanto aos "gélidos e belos" versos, o próprio poeta afirma, em entrevistas e cartas, querer, em suas "versificações”, emular os
*(ŞERBAN, Liliana. Ion Barbu - Dan Barbilian: maximum de gând în minimum de expresie. Conferinţa Naţională de Învăţământ Virtual, Ediția a V-a, 2007: 229.)

* (MINCU, Marin. Opera literară a lui Ion Barbu. Bucureşti: Cartea Românească, 1990: 338.)

* (BARBILIAN, Dan. Algebră axiomatică. Bucureşti: Editura Didactică şi Pedagogică, 1988: 5.)

* (MANDICS, Gyorgy. Ion Barbu, în 10 poeme. Bucureşti: Editura Dacia, 2003: 7.)

* (Idem.)

*(RUJA, op. cit.: 11.) 
* (BARBU, lon. Pagini de proză. Ediţie, studiu introductiv şi note de Dinu Pillat. Bucureşti: Editura Pentru Literatură, 1968: 39-40.)

(* BARbu, Ion. Poezii. Chişinău: Editura Prut International, 2003: 17.)

* (MINCU, op. cit.: 338 .)

* (Ibidem: 24-25.)

* (BARBU, op. cit., 1968: 84-87.)

*(Ibidem: 105-106.) "estados absolutos do intelecto e da visão: o estado geométrico e, para além dele, o êxtase".* "Nadir latente"* perdido no elevado candor do Conhecimento, a poesia barbiana é uma Odisseia em um mundo de Logos, sem no entanto excluir a emoção: "Todos reconheciam seu talento, mas não viam sua emoção e seu sentimento [Para os críticos da época] Barbu era um poeta de formas glaciais. Parnasianismo impassável. Confusão - uma confusão gerada pela delimitação da noção de emoção".* A lírica barbiana é mais sutil, apartada dos „lamentos melódicos” de poetas comuns: "Emoçóes intelectuais também existem. Mas são raras e menos acessíveis. Portanto, mais preciosas".* A palavra "flamejante e profética", a "poesia preguiçosa”, o "banal reabilitado"* não fazem parte da fómula lírica de Barbu: "Há um nível de experiência poética no qual o verso se prova rigor e fervor, e não uma interjeição elaborada ou uma celebração mais ou menos harmoniosa”.* O eixo da poética de Barbu é um romantismo diferente, um romantismo gnosiológico.

Por conseguinte, a poesia, em termos barbianos, é um "jogo"; não um jogo derivado do real, mas sim do reflexo da realidade "no espelho", isto é, no espírito: é "espelhada", um jogo superior, jogo de Ideias, Essências, de Conhecimento puro. Para além do jogo original das aparências, o poeta busca um jogo espelhado de seus significados. A poesia, portanto, torna-se uma transcendência do real em signos arquetípicos platônicos. A arte poética de Barbu se inicia pela compreensão abstrata do mundo, não se preocupa com as coisas: a realidade imediata, o evidente, as qualidades contingentes são matéria irreconhecível para a arte.

De modo a esboçar uma visão da unidade universal e responder às questóes primordiais da humanidade, Ion Barbu defende o retorno da poesia à função original que a ode pindárica exercia na Antiguidade. O próprio Barbu afirma que o que pode parecer modernismo em sua obra não passa de um entrelaçamento com o passado mais remoto da poesia: a ode pindárica. A geometria na obra de Barbu, portanto, mais do que uma noção científica, é um conceito, um princípio, uma maneira de perceber o mundo, uma categoria estilística. As Odes de Píndaro, os Elementos de Euclides, os Estoicos de Apolônio, as Coleção matemática de Pappus tornaram-se símbolos da Grécia apolínea: "Afinal, o pensamento grego é expresso não só por meio dos mitos, ficcionalmente, mas também diretamente, em teoremas. $\mathrm{O}$ portão através do qual podemos adentrar o mundo grego e discuti-lo - e sem esse conhecimento, 
creio, a cultura de um indivíduo não pode ser considerada plena - não é necessariamente Homero. A geometria grega é um portão mais largo, através do qual o olho pode vislumbrar uma paisagem austera, mas essencial.*

O poeta e matemático propóe uma fórmula original para este novo humanismo: o que diferencia o humanista clássico do moderno é precisamente a ênfase dada à "formação matemática" .* Partindo da visão geométrica de Apolônio, como expressão da intuição das essências condensadas em um único princípio sintético, o humanismo barbiano propóe uma configuração de mundos possiveis. O eixo fundamental deste novo humanismo é a abertura para a inovação, para interpretaçóes prováveis: "No novo humanismo, a probabilidade, como uma abertura dialética no plano do método, torna-se fundamental, em comparação ao hieratismo da geometria grega tornada dogma filosófico".* Barbu fala da relação entre conceitos matemáticos e sua poesia nos seguintes termos: "Somos contemporâneos de Einstein, e ele rivaliza com Euclides na imaginação de universos abstratos, então nós inevitavelmente devemos rivalizar com o demiurgo na imaginação de mundos prováveis".*

O espírito grego revela-se em todo seu esplendor na poesia de Barbu, em seus poemas encontramos uma Hellas misteriosa. $\mathrm{O}$ estado geométrico, o rigor e a luz apolínea não são as únicas coordenadas segundo as quais se move sua obra. A bipolaridade da alma grega também conta com o lírico dionisíaco como forma de expressão: catarse, eternidade cósmica, a imanente luz dos sonhos, o que aproxima Barbu dos românticos. "Os aspectos culturais de Hellas são vistos nos temas e motivos frequentes em sua poesia, mas também em um elemento essencial na configuração de sua poética. A relação com a Grécia antiga é relação com a tradição...”* O poeta também manifestou publicamente sua afinidade com a obra dos grandes românticos. Em sua própria poesia, ele se deteve no aspecto gnosiológico e nos mistérios órficos gregos. Alguns historiadores literários, como Marin Mincu, em Ion Barbu's Literary Works (Editura Cartea Românească, 1990), falam da possibilidade de categorizar o poeta como um expressionista, já que através de uma "explosão de energia latente", de uma "visão trágica do destino humano", o expressionismo torna-se "a última tentativa crepuscular da arte"* de sobreviver à época pragmática que lhe seguiria. Sincronicamente, Ion Barbu é mais expressionista do que romântico, dada sua aspiração ao absoluto e o "gnosticismo" da visão que expande a perspec-
* (BARBILIAN, Dan. Ope-

ra matematică, vol. I. Geometrie. Bucureşti: Editura Didactică şi Pedagogică, 1967: 11-13.)

* (Idem.)

*(MINCU, op. cit., 1990: 89.)

*(BARBU, op. cit., 1968: 39.)

*(RUJA, op. cit., 2008: 11.)

* (MINCU, op. cit., 1990: 210-211.) 
* (ŞERBAN, op. cit., 2007: 233.)

* (Ibidem: 211.) tiva romântica. Ao explorar mistérios arcaicos (egípcios, gregos) e os mistérios da matemática moderna, o poeta se coloca na hipóstase de Píndaro (que era um iniciante de Hermes Trismegisto, ao retrabalhar o Egito através da lira órfica). Hermes Trismegisto (deus da Revelação, nome dado pelos neoplatônicos ao deus egípcio Toth - aquele que guarda o mistério da Criação e do Conhecimento), o poeta Ion Barbu encripta o mistério da existência usando uma metáfora, um símbolo.* $\mathrm{O}$ hermetismo do poeta tende a concretizar um sistema de signos autônomo/único, como no romantismo. "Através da fórmula do romantismo gnóstico, podemos ter uma visão sintética do lirismo de todas as eras."*

O contato com a poesia expressionista alemã deu a Barbu uma compreensão diferente do fazer poético e uma noção nova do que seja um poeta: "The poet raises the sum/ Of dispersed harps, harps you loose in counter-flight" ("Out of a clock, inferred..."), isto é, ele se torna um arquétipo e seu gesto é arquetípico. $\mathrm{O}$ tema, os heróis, o conflito, o sujeito, tudo tem por fundamento um conhecimento essencial sobre o mundo e, por analogia, sobre o universo: "And the song is hazed: hidden, as only the seal When the medusae walk under the green bells" ${ }^{3 *} \mathrm{O}$ próprio Barbu reconhece, no poema "Out of a clock, inferred", a influência da poesia clássica, da ode pindárica, pela harmonia e pelo equilíbrio composicionais, mas também pela associação simbólica: "harpas", "sinos", "canto", assim como pelos conceitos de mimesis ("jogo espelhado") e catharsis ("cerúleo curativo"), tomados da Poética de Aristóteles. A necessidade de objetividade determinava que os poetas do Parnaso usassem formas fixas. Precisamente por isso, na maioria dos poemas desta fase, Barbu usou a forma do soneto.

Romântico por inspiração e por natureza, clássico por conceito e expressão, esboçando as formas de um novo humanismo como ponto de partida para o pensamento moderno, o poeta gênio e matemático junta à sua criação uma nova e fundamental dimensão: a essencialização, a máxima condensação da expressão artística. Em sua opinião, tudo o que é supérfluo deve ser cuidadosamente eliminado, porque nenhuma linguagem é possível quando se fala de essência, a não ser a língua elíptica dos teoremas. Ele "retira de

2 "O poeta soma/ as harpas dispersas, harpas que se perdem em contravoo". (N. do T.)

3 "E o canto se enevoa: escondido, como só o mar/ Quando as medusas caminham sob os sinos verdes" (N. do T.) 
uma certa noção da arte dos teoremas, que Gauss considerava ,um texto majestoso', como uma inscrição, o laconismo do qual deriva sua longevidade".* O ponto fulcral do pensamento de Barbilian é a fórmula "O mínimo de fórmulas cegas com o máximo de fórmulas visionárias", a definição de Minkovsky para o hermetismo gaussiano.*

O crítico Marin Mincu aponta uma sutil diferença entre dois conceitos, ermetismo e hermetismo, ${ }^{4 *}$ ressaltando novamente o caráter único da obra de Barbu. Diferentemente de Mallarmé, cuja mensagem poética é puramente hermética, e portanto despida de qualquer lirismo, Ion Barbu criou uma poesia que revela o mundo através de seu próprio sistema de símbolos cujos significados geram um novo lirismo. "Ermetismo" significa tudo aquilo que não é revelado diretamente, mas somente após a iniciação, de modo que a mensagem da obra barbiana não é "comunicada" de maneira direta. Sua compreensão pressupóe uma iniciação no universo do Conhecimento, construído pelo poeta de acordo com as leis rigorosas da geometria e "encriptadas" pelo matemático seguindo a fórmula gaussiana de significação máxima com o mínimo de signos. A mensagem hermética pode ser comunicada através de múltiplas formas artísticas, isto é, uma linguagem aberta a diversas interpretaçôes. A concentração máxima da fórmula poética possibilita diversas perspectivas para a decifração do mistério.* Embora "encerrada" nas fronteiras do conhecimento abstrato, o ermetismo poético é o ponto de partida para uma obra aberta a múltiplas interpretaçóes que recriam e desvelam os sentidos do discurso poético. Sobre essa poesia, inicialmente mal compreendida, o próprio Barbu diz que, se um poema "admite uma explicação, racionalmente, admite uma infinidade. Uma exegese não pode ser absoluta. Um poeta, de acordo com certa matemática, pode dar não uma, nem duas, mas inúmeras explicações para um poema obscuro"* $\mathrm{O}$ ermetismo propóe, assim, uma visão única da ordem universal, absolutamente determinada. A obra pode sugerir uma infinidade de sentidos, aberta à recriação interpretativa do receptor, e o leitor pode entendê-la da maneira que desejar.

\section{Traduçâo de Victor Heringer (Mestre em Teoria Literárial UFRJ)}

\footnotetext{
4 "Ermetismo" é a forma romena da palavra "hermetismo", jogo de palavras intraduzível. (N. do T.)
}

* (Ibidem: 192.)

* (Idem.)

* (MINCU, op. cit., 1990: 101-105.)

* (Idem.)

* (BARBU, op. cit., 1968: 54-55.) 
Virginia Popović nasceu na Sérvia, em 1975, e pertence à minoria nacional romena no país. É professora do Departamento de Estudos romenos na Faculdade de Filosofia da Universidade de Novi Sad, onde fez seu doutorado sobre a obra do poeta moderno romeno Ion Barbu. Tem trabalhos publicados sobre os poetas simbolistas, modernistas e pós-modernistas romenos e sérvios, bem como sobre a literatura romena contemporânea da Voivodina. É membro do comitê editorial de diversas revistas na Sérvia e na Romênia. E-mail: popovic.virdjinija@gmail.com 